\title{
Linked-Class Problem-Based Learning In Engineering: Method And Evaluation
}

Emily M. Hunt, Ph.D., West Texas A\&M University, USA

Pamela Lockwood-Cooke, Ph.D., West Texas A\&M University, USA

Judy Kelley, West Texas A\&M University, USA

\begin{abstract}
Problem-Based Learning (PBL) is a problem-centered teaching method with exciting potential in engineering education for motivating and enhancing student learning. Implementation of PBL in engineering education has the potential to bridge the gap between theory and practice. Two common problems are encountered when attempting to integrate PBL into the undergraduate engineering classroom: 1) the large time requirement to complete a significant, useful problem and 2) the ability to determine its impact on students. Engineering, mathematics, and science professors at West Texas A\&M University (WTAMU) have overcome the large time commitment associated with implementation of PBL in a single course by integrating small components of the larger project into each of their classes and then linking these components with a culminating experience for all the classes. Most of the engineering students were concurrently enrolled in the engineering, mathematics, and science classes and were therefore participating in all activities related to the project. This linked-class PBL experience addressed course concepts, reinforced connections among the courses, and provided real-world applications for the students. Students viewed the experience as beneficial, increasing their understanding of content and applications in each discipline. This paper provides details about implementation and evaluation of one PBL project and how difficulties in evaluation of the linked-class PBL experiences are being addressed.
\end{abstract}

Keywords: Problem-Based Learning; Engineering Education; Evaluation

\section{INTRODUCTION}

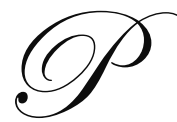

roblem-Based Learning (PBL) is possibly the most important and powerful pedagogical innovation in history [1-4]. PBL has become increasingly popular in K-12 and higher education worldwide since it was first introduced in medical education in the late 1960's [1]. However, it has not gained significant popularity in engineering curricula due to the large time-scale needed to solve complex engineering problems and the difficulties associated with assessment of its impact on students. This paper examines a new method for incorporating PBL into undergraduate engineering curricula through a linked-class approach involving math and physics courses as well as engineering courses. Studies indicate that the application and integration of foundation disciplines such as mathematics and physics into practical engineering applications increases student engagement in the learning process [2-5]. Development of strategies for successful implementation of PBL in engineering curricula is very important to engineering education because of the potential positive impact on student learning.

Engineering faculty at West Texas A\&M University (WTAMU) understood this need for implementation of PBL in their curriculum, and NSF funding (DUE 0622442) from the Science, Technology, Engineering, and Mathematics Talent Expansion Program (STEP) for the WTAMU project Increasing Numbers, Connections, and Retention in Science and Engineering (INCRSE) provided the framework for engineering, mathematics, and physics faculty to pilot an innovative approach for linking their courses to engage students in a PBL experience. An important aspect of this approach is how it overcomes the large time commitment required for implementing PBL in a single engineering course by dividing a large engineering problem into smaller problems which can be addressed not only in engineering but also in mathematics and physics. This linked PBL approach makes the time commitment 
manageable for all three courses and results in beneficial experiences for students in each class. At the conclusion of the PBL experience, the participating engineering, mathematics, and physics faculty bring all the students together for an event which celebrates the contribution of each class to the large project and reinforces the linked aspects of the project, connections between the three disciplines, and the importance of interdisciplinary teamwork. The following sections of this paper examine (1) this linked-class PBL approach; (2) a PBL experience piloted in Engineering Statics, Calculus II, and Engineering Physics; and (3) efforts to assess the impact of the linked-class PBL approach.

\section{LINKED-CLASS PBL}

The linked-class PBL approach is based on the connections between engineering, mathematics, and physics. Embedded in complex engineering problems are smaller problems from mathematics and physics. Mathematical problem solving within engineering requires knowledge of fundamental mathematical concepts, problem solving skills, and an ability to apply these concepts [6]. Physics problem solving in engineering requires the knowledge of settings in which particular concepts and algorithms are to be applied. Implementation of the linked-class PBL approach is a logical extension for some of the problems that students already work in calculus and physics. These mathematics and physics problems could be viewed as part of a more complex engineering problem and individually require a much smaller time commitment than the engineering problem.

As part of the NSF-funded INCRSE project efforts to enhance student learning, WTAMU engineering, mathematics and physics began implementation of a PBL experience for their students in Engineering Statics, Calculus II, and Engineering Physics. A large engineering problem was introduced to the students in these classes, and then different pieces of the problem were solved concurrently in each of the classes. This created problemsolving opportunities on a small time scale in the linked classes that were then connected to solve a significant engineering problem that would normally have taken a large amount of class time in the engineering course. In each class, group work with directed individual or interactive tasks was facilitated through teacher-guided discussions.

A key advantage of the linked-class approach is the reduced time commitment required for implementation of PBL in an engineering course. For example, a PBL experience that would have taken 2-3 weeks to complete in the engineering course could be completed in about 1 week with the linked-class approach. Another benefit to the linked-class approach rests in the interdisciplinary nature of the efforts which provided students the opportunity to see the real-world engineering applications of what they learned in mathematics and physics classes. Effective implementation of the linked-class PBL requires a great deal of planning and coordination between faculty members. Appropriate scheduling of the activities in each class is critical for the success of the linked-class PBL experience. It is also critical that faculty coordinate to ensure that the same nomenclature and terminology are used in each class.

WTAMU's size added another dimension to the implementation of the linked-class PBL approach. While most of the students involved in the PBL experiences were engineering majors, there were also mathematics majors and science majors in some of the linked classes. Therefore, not all students were enrolled in each of the three linked classes, and some of the students had already successfully completed some of the courses. Faculty used a variety of strategies to maximize the impact of the PBL experience for students not enrolled in all three classes. Student groups in calculus and physics were created to insure that each group included at least one student concurrently enrolled in all three classes. Faculty worked with these student groups to summarize the activities in the other courses and minimizing gaps that might occur for students not enrolled in the other courses. These strategies were known to be somewhat successful because during assessment focus groups, students not enrolled in all three classes shared how they had benefited from the linked-class PBL experience and also provided suggestions for more opportunities for connections with activities in the other classes.

\section{LINKED-CLASS WATER ROCKET PBL EXPERIENCE}

Over the last few years, WTAMU faculty have used various projects as the basis for their implementation of the linked-class approach to PBL in engineering, mathematics, and physics classes. The project that has thus far received the most attention from faculty and students is the design and analysis of a water rocket. The study of 
rocket motion has been used extensively in the past to motivate students to learn physics [7-11]. Combined with the study of engineering dynamics and numerical analysis, the project can provide students with the opportunity to solve many interesting, real-world problems. Students who have worked on rocket problems in the past have commented that the ability to analyze and predict the rocket's motion was exciting and motivational [7].

This is not a new project, but the use of the linked-class PBL approach to the project was completely novel. The students in the linked classes were assigned the problem of building, analyzing, and testing the motion of an airpumped, water-propelled rocket. They worked in groups to outline their procedures, develop a numerical model, and design, construct and test a water-propelled rocket.

Faculty used the annual end-of-semester cookout sponsored by the engineering student organizations (Figure 1) as an opportunity to bring the classes together for a rocket launch and also as a way to showcase the linked-class PBL approach to other students and faculty. Having this kind of audience for the launch was exciting for the students who had participated in the PBL experience and motivated them to perform to the standard of the other groups who had built rockets. Class specific details about these tasks are provided below and provide specific examples of how the linked-class PBL approach can be implemented

\section{Engineering Physics}

Students were first introduced to the rocket problem in the engineering physics class when they began to study the equations of motion that describe a rocket's trajectory. A rocket in flight will obey Newton's Second Law which states that the sum of forces acting on the rocket is equal to the mass of the rocket times the acceleration of the rocket. During launch, three forces will act upon the rocket: the gravitational force, aerodynamic drag, and the upward thrust produced by the expelled water. Students worked in groups to develop the governing equations for the theory of rocket motion.

\section{Calculus II}

Calculus II students reviewed the theory of rocket flight including Bernoulli's Equation, the Rocket Equation, and Newton's Second Law which was initially presented in Engineering Physics and then combined this information with their newly acquired knowledge of differential equations to set up the system of differential equations describing the rocket flight. They solved the system using the ODE 45 differential equation solver found in Matlab and graphed the theoretical flight path of the rocket from the solution. Initially the students compared the maximum height found in the model trajectory to the actual maximum height of the constructed rockets on the day of flight. To further the investigation, the students then explored their solution to the differential equation by plotting the position, velocity and volume of air and water in the rocket over the duration of the flight. The students explored the effect of the drag coefficient, the initial volume of water in the rocket, the initial pressure in the rocket as well as the effect of neglecting the mass of the water in the rocket on the flight trajectory.

\section{Engineering Statics}

This problem was introduced in the second half of the semester in order to serve as motivation for the Dynamics course that the students would take the next semester. Students worked in groups to design and construct water-propelled rockets. Their task was to build a rocket from a 2 liter coke bottle and find, for a given maximum pressure, the parameters for the shape and size of the bottle, the amount of water and the size of the outflow opening that would maximize the height during flight.

On the day of the launch, the engineering students used a triangulation method to measure the height of flight for each rocket launched. Rockets were launched several times to allow a comparison of the theoretical results obtained in physics and calculus through their numerical analysis to the results of their designed constructed rocket. Each group was then responsible for analyzing the results and comparing them to their predicted height. A final, formal engineering report was then required from each group that included the work performed in the calculus and physics classes. 


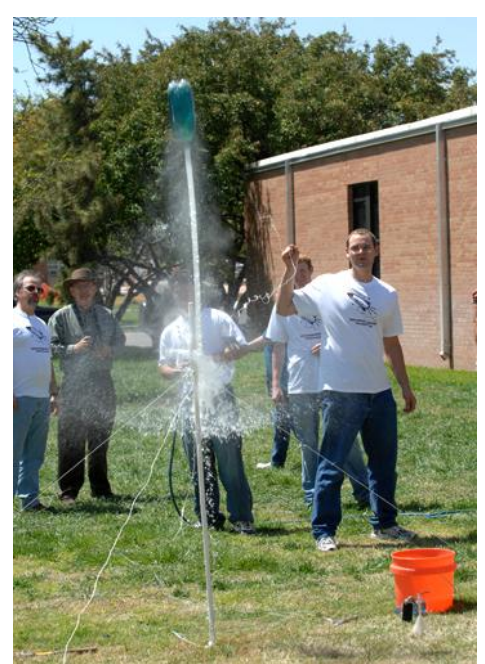

Figure 1: Rocket launch

\section{INITIAL EVALUATION OF LINKED-CLASS PBL}

Collection of data related to the student impact of the linked-class PBL has been a learning process for faculty leading these activities. During their first attempt to integrate PBL in the linked-classes, these faculty members were primarily focused on the activities themselves and the extensive coordination required across classes and gave only last minute attention to evaluation of the implementation process for the linked-class PBL and its impact on student learning.

Since this activity was part of the INCRSE project, a meeting between the faculty and the West Texas Office of Evaluation and Research (WTER), the external evaluators of INCRSE, was held shortly before implementation of the linked-class PBL was to begin. Realizing that it was important to gather data that directly measured student learning as well as students' perceptions about their learning, they decided to create pre/post survey instruments which would include content questions created by the faculty and student perception questions developed by WTER.

Examples of content questions included on both the pre- and post-tests were:

- Match each of the following force diagrams with one of the given situations. Assume that all force vectors have the same magnitude and that air resistance can be ignored unless stated otherwise.
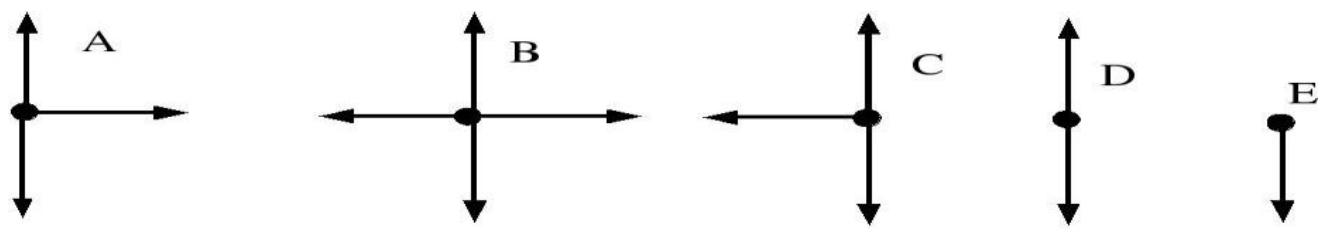

- Rocket sitting on the pad before launch

- Rocket traveling upward after its fuel has burned out

- Rocket at its highest point

- Rocket falling from maximum height before its parachute opens

- Rocket falling at constant speed after its parachute has opened

- Constant upward force is represented by $\mathrm{F}_{\mathrm{T}}$. The motor burns until time $\mathrm{t}=\mathrm{t}_{1}$. The rocket reaches its maximum altitude at a later time $t_{2}$. After it has fallen for a while, it deploys a parachute at time $t_{3}$ and drifts downward at a constant speed under the influence of the parachute. Assume this speed remains the same as 
it was at $t_{3}$. Write equations for the velocity and acceleration at the indicated times in terms of the given quantities $\mathrm{m}, \mathrm{g}, \mathrm{F}_{\mathrm{T}}, \mathrm{t}_{1}, \mathrm{t}_{2}, \mathrm{t}_{3}$, and $\mathrm{t}$, where $\mathrm{t}$ is the time elapsed since the launch at $\mathrm{t}=0$. You may state later answers in terms of earlier ones. (e.g. $\mathrm{v}\left(\mathrm{t}_{2}<\mathrm{t}<\mathrm{t}_{3}\right)=2 \mathrm{v}\left(\mathrm{t}_{2}\right)$ is permissible if you have already shown what $\mathrm{v}\left(\mathrm{t}_{2}\right)$ is). Show your calculations on the back of this page. Assume all motion is vertical (i.e. this is a onedimensional problem).

\begin{tabular}{ccc} 
Time & Velocity & Acceleration \\
\hline $0<\mathrm{t}<\mathrm{t}_{1}$ & \\
\hline $\mathrm{t}_{1}<\mathrm{t}<\mathrm{t}_{2}$ & \\
\hline $\mathrm{t}_{2}$ & \\
\hline
\end{tabular}

\begin{tabular}{ccc} 
Time & Velocity & Acceleration \\
\hline $\mathrm{t}_{2}<\mathrm{t}<\mathrm{t}_{3}$ & \\
\hline $\mathrm{t}>\mathrm{t}_{3}$ & \\
\hline
\end{tabular}

These efforts to collect data related to student learning did not produce good information. Faculty learned the following lessons from this initial data collection effort:

- Students will not give a strong effort to respond to content questions if there is not a grade given to the assignment.

- In administration of pre/post tests, great attention must be paid to ensuring that students complete both the pre- and post-tests and that data are identified in a way to allow paired data analysis.

- It is important to start early to develop an appropriate evaluation plan for future linked-class PBL implementation.

On the post-test, students did provide the following information about their perceptions of their learning. All students indicated:

- $\quad$ Participation in the rocket project enhanced their understanding of math, physics, and/or engineering content and their real-world applications.

- $\quad$ They want to participate in other projects like the rocket project.

- $\quad$ They believe students benefit from participation in projects that integrate content from different courses as was done in the rocket project.

\section{REVISIONS IN EVALUATION PLAN FOR LINKED-CLASS PBL}

Since the initial implementation of linked-class PBL, faculty have developed and integrated other projects, such as the pie launcher project, in their classes. They have worked more closely with WTER to improve the original surveys and have also added student focus groups to gather more information from students.

WTER introduced the faculty to the NSF-supported Student Assessment of Learning Gains (SALG) website, www.salgsite.org [12]. On this website, faculty can modify existing SALG online survey instruments addressing students' perspectives about their learning and the impact of different class components. Since answering SALG survey questions facilitates student reflection about their learning, this instrument is a good choice to use in evaluation of PBL which focuses more on learning to learn and less on a particular body of knowledge.

Because of limited access to computer labs, the faculty chose to administer a paper survey during class. The survey included questions modeled after the SALG instrument. Examples of questions addressing the pie launcher project which were included on the end of semester surveys in the linked Engineering Statics and Calculus II classes were:

- $\quad$ Use the provided scale (very much help, much help, moderate help, a little help, no help) to indicate how much each of the following helped your learning.

- The way the project fit together with other parts of the class

$\circ \quad$ Working with other students on the project

- Linking the project in this Calculus II class with the Engineering Statics class

- Use the provided scale (a great deal, a lot, somewhat, a little, not at all) to describe the extent of the gains you made in each of the following areas as a result of your work on the project. 
- Ability to use math to solve problems

- Understanding engineering concepts

$\circ$ Applying engineering concepts

$\circ \quad$ Enthusiasm for becoming an engineer

- Understanding of what engineers do

- $\quad$ Use the provided scale (a great deal, a lot, somewhat, a little, not at all) to indicate how much the project helped you learn about each of the following concepts and related skills

$\circ$ Using elastic material or springs to generate a force to launch a projectile

- Effect of external forces on the motion of a projectile

- Newton's $2^{\text {nd }}$ Law, $F=$ ma

Fifteen students completed this Engineering Statics survey and 31 completed the Calculus II survey. Some of the key findings of the surveys, WTER recommendations for consideration, and/or faculty response to the findings and recommendations were:

- When asked how much help the way the project fit together with the other parts of the class provided to their learning, less than $50 \%$ of the engineering class responses indicated very much help or much help. Faculty need to consider giving more attention to integrating the project into the class in a way that facilitates student learning.

- $\quad 80 \%$ of the Engineering Statics survey respondents indicate working with other students on the project provided either very much help or much help to their learning. Faculty will continue to facilitate group work on projects.

- $\quad 87 \%$ of the Engineering Statics survey respondents agreed that students benefit from participation in projects. However, only $26 \%$ of the Calculus II survey respondents viewed linking the project in their calculus class with the engineering class to be very much help or much help to their learning. Calculus faculty should identify ways to help students realize how valuable this connection to engineering applications can be to their understanding of calculus.

- $\quad$ Over 50\% of the Engineering Statics respondents indicated having gains of a great deal or a lot in their (1) ability to use math to solve problems (53\%); (2) understanding of engineering concepts (73\%); (3) applying engineering concepts (60\%); (4) enthusiasm for becoming an engineer (67\%); and (5) understanding of what engineers do $(54 \%)$.

- At least $80 \%$ of the Engineering Statics survey respondents indicated their participation in the project helped their learning a great deal or a lot about using elastic material or springs to generate a force to launch a projectile $(80 \%)$ and about the effect of external forces on the motion of a projectile $(87 \%)$. Slightly over $60 \%$ of the Calculus II survey respondents shared the same kind of gains in their learning about Newton's $2^{\text {nd }}$ Law as a result of their participation in the project.

In order to gather more information about students' perceptions of the value added to their learning by the linked-class PBL, WTER conducted three focus groups with students at the end of the semester in which the pie launcher project was conducted. One focus group involved students enrolled in both Engineering Statics and Calculus II; another group with students only enrolled in Engineering Statics; and the third group only enrolled in Calculus II. Faculty were concerned about the perceptions of students not enrolled in both the engineering and calculus classes so dividing the students into these three groups allowed information to be collected from students not enrolled in both classes. Key findings from the focus groups and possible action by faculty responses to the findings were:

- $\quad$ Students in all three focus groups believed their participation in the linked-class PBL experience was beneficial and increased their understanding of content and its application in real world situations. The connections made between disciplines were also viewed as very helpful and important.

- $\quad$ Students valued the opportunity to work in groups, not just because of sharing knowledge but also because of the opportunity to develop friendships.

- $\quad$ Students in all three groups expressed interest in participating in similar projects in the future.

- The issue of the cost of materials for building their pie launcher was raised in the focus group of students in 
both classes and in the focus group of students only in the engineering class. Faculty need to do a better job of communicating with students how to get reimbursed for expenses related to the projects.

- A student in the engineering only focus group compared the pie launcher project with the rocket project since he/she had participated in both. In the rocket project, they measured how high the rocket flew and then compared their theory-based predictions with the actual data. He/she suggested collecting more data about the pie launching in order to make comparisons like they did in the rocket project. Faculty need to ensure that students do appropriate and complete data collection with future projects.

- $\quad$ The calculus-only focus group suggested ways that students who are not enrolled in all the linked classes could be included in more of the tasks associated with the linked-class PBL projects. For example, they could have been included in the actual building of the pie launcher since it was built outside the engineering class time and at a time when the calculus-only students could participate. These students also suggested using more of the math principles they were learning in Calculus II in the design and building of the pie launchers. With future linked-class PBL projects, faculty need to identify opportunities for all students to be engaged in as much of the project as possible.

\section{DIRECT MEASUREMENTS OF STUDENTS' LEARNING GAINS}

Faculty implemented the linked-class PBL approach in one section of Introduction to Engineering and one section of Calculus I in which they had worked with administration to have all students co-enrolled. A pipeline project based on the classic Snell's Law refraction type problem that appears in some variation in most calculus texts was integrated into both the engineering and calculus class. In the engineering class, the students were engaged in a geometric approach for modeling the problem. In the calculus class, the project was introduced when the students were learning about optimization. On the final exam in the calculus class, students were given the following problem:

Points $A$ and $B$ are 6 miles apart on a straight coast. A man in a rowboat is 2 miles from the coast off of point A. If he can row 4 mph and run $5 \mathrm{mph}$, at what point $P$ should he land his rowboat in order to reach point $B$ in the least possible time? Be certain you justify that your critical point is the minimum you are searching for.

Of the 23 students in the linked classes, 15 (65\%) received full credit for their answers to the question, 2 received partial credit, and 6 received no credit.

This same question was included on the final exam of the non-linked Calculus I section. Of the 32 students in the non-linked class, $15(46 \%)$ received full credit, 1 received partial credit, and 16 received no credit.

\section{NEXT STEPS IN EVALUATION OF LINKED-CLASS PBL}

Faculty plan to use their experiences with evaluation of linked-class PBL as the foundation for developing a more rigorous evaluation plan for future projects. They will work with WTER to develop survey questions using the revised SALG instrument as a model. The SALG instrument was revised to include the following five overarching questions provided on the SALG website:

- $\quad$ How much did the following aspects of the course help you in your learning? (Examples might include class and lab activities, assessments, particular learning methods, and resources.)

- $\quad$ As a result of your work in this class, what gains did you make in your understanding of each of the following? (Instructors insert those concepts that they consider most important.)

- $\quad$ As a result of your work in this class, what gains did you make in the following skills? (A sample of skills includes the ability to make quantitative estimates, finding trends in data, or writing technical texts.)

- $\quad$ As a result of your work in this class, what gains did you make in the following? (The sub-items address attitudinal issues such as enthusiasm for the course or subject area.)

- As a result of your work in this class, what gains did you make in integrating the following? (The sub-items address how students integrated information.) 
Focus groups will continue to be used to collect information about students' perspectives related to the value of the linked-class PBL and their suggestions for improving these projects. Faculty and WTER will work together to review the results of surveys and then develop focus group questions and strategies for formation of focus groups in order to clarify and enrich what students have indicated on the surveys.

To strengthen the data related to student gains in understanding of content knowledge and in ability to perform various tasks, faculty will continue to develop questions focused on "big ideas" and "demonstration of skills and abilities." Ideally, these questions would be embedded in final exams and administered to students who have participated in linked-class PBL projects as well as students taking the same course but not in the section in which linked-class PBL projects are implemented. This would allow comparisons between participants in linked-class PBL activities and non-participants. An example of this kind of question related to either the rocket or pie launcher projects that could be added to a final exam is:

- Given the acceleration, initial velocity, and initial position of a body moving on a coordinate line, find the body's position at time t. $a=9.8 ; v(0)=-3, s(0)=0$

Faculty also plan to track students' progress in their STEM classes as they move toward their degrees after they have participated in the linked-class PBL projects and make appropriate comparisons to students who did not participate in linked-class PBL.

\section{CONCLUSIONS}

The use of linked-class PBL experiences successfully addresses the time constraints of implementing PBL in engineering courses. However, a commitment of faculty teaching the linked classes to planning and coordinated implementation of project activities is essential for the success of the linked-class PBL approach. Student evaluations are supportive of this approach, but more data based on students' perceptions, direct measurement of student learning, and tracking of success in other courses of linked-class PBL participants and non-participants are needed before determination of the long-term impact of participation in linked-class PBL can be made. Faculty must also be committed to continued implementation and refinement of evaluation methods and to use of evaluation results to improve the impact of linked-class PBL projects.

\section{AUTHOR INFORMATION}

Dr. Emily M. Hunt is an associate professor of mechanical engineering at West Texas A\&M University. Her research focus is energetic nanomaterials and undergraduate engineering education.

Dr. Pamela Lockwood-Cooke is an associate professor of mathematics at West Texas A\&M University. She is the principal investigator of the National Science Foundation Science Talent Expansion Program Increasing Numbers, Connections, and Retention in Science and Engineering (INCRSE).

Ms. Judy Kelley is the director of West Texas Evaluation and Research (WTER) and the associate director of the Texas Engineering Experiment Station. She does evaluation for several NSF-funded educational research projects in Texas.

\section{REFERENCES}

1. Perrenet, J.C., Bouhuijis, P.A., and Smits, J.G.M.M. "The Suitability of Problem-based Learning for Engineering Education: theory and practice," Teaching in Higher Education 5 (33) (2000) 345-358.

2. Costa, L.R.J., Honkala, M., and Lehtovuori, A. "Applying problem-based learning approach to teach elementary circuit analysis," IEEE Transactions on Education 50 (1) (2007) 41-48.

3. Woods, D.R., "Problem-based learning for large classes in Chemical Engineering," Bringing Problembased learning to Higher Education: theory and practice, (1996) 91-99.

4. Eugene, Christian. "How to each at the university level through an active learning approach: Consequences for teaching basic electrical measurements," Measurement 39 (2006) 936-946. 
5. Cawley, P. “A Problem-based Module in Mechanical Engineering,” The Challenge of Problem Based Learning, (1991) 177-185.

6. $\quad$ Perrenet, J.C. and Wolters, M.A.D., "The art of checking: a case study of students erroneous behaviour in introductory Algebra," Journal for Mathematical Behaviour 13 (1994) 335-358.

7. Finney, G.A. "Analysis of a water-propelled rocket: A problem in honors physics," Am. J. Phys. 68 (3) (2000) 223-227.

8. Nelson, R.A., and Wilson,M.E., "Mathematical Analysis of a Model Rocket Trajectory," Phys. Teach. 14 (1976) 150-161.

9. $\quad$ Gowdy, R.H. "The Physics of perfect rockets," Am. J. Phys. 57 (1995) 322-325.

10. Lodefink, Steve. "Soda Bottle Rocket: Liquid Fuel Alternative," Makezine 5 (2007) 80-89.

11. Kamiel Martinet, web design/ developer. "Water-Rockets." http://www.martinet.nl (2007).

12. Seymour, E. "Student Assessment of Learning Gains" website originally www.wcer.wisc.edu/salgains/instructor but www.salgsite.org as of June 30, 2008. 
NOTES 